\title{
“Who Is Doing My Surgery?" Patient Preferences Regarding Trainee Involvement in Surgical Care
}

\author{
Daniel B. Moore, MD ${ }^{1,2}$ David J. Harris III, MD ${ }^{1,2}$ Laura Coyne, MD ${ }^{1,2}$ Richard J. Kryscio, PhD ${ }^{3}$ \\ Qiwen Kang, MS ${ }^{3}$ Marla Davis, MD ${ }^{1,2}$ \\ ${ }^{1}$ Department of Ophthalmology, University of Kentucky, \\ Lexington, Kentucky \\ 2 Department of Ophthalmology, Veterans Affairs Medical Center, \\ Lexington, Kentucky

\begin{abstract}
Address for correspondence Daniel B. Moore, MD, Department of Ophthalmology and Visual Sciences, University of Kentucky, 110 Conn Terrace, Suite 550 Lexington, KY 40508

(e-mail: daniel.b.moore@uky.edu).
\end{abstract}

${ }^{3}$ Department of Statistics, University of Kentucky,

Lexington, Kentucky

J Acad Ophthalmol 2019;11:e30-e34.

\begin{abstract}
Purpose There are no uniform standards to inform patients to what extent trainees are involved in their care. This may lead to inequities in sharing the potential risks associated with receiving care in an academic setting. This study was designed to determine patients' level of knowledge of the medical education system, their preferences regarding who provides treatment, and how strongly they would react if they found certain members of the care team were involved without their consent. Design This study is a prospective, nonrandomized, and observational survey of a convenience sample.

Methods Consecutive patients referred for a cataract surgery evaluation to the Veteran's Affairs Ophthalmology Department in Lexington, KY between 2015 and 2017 were recruited.

Results Ninety-six of 113 eligible patients (response rate 85\%) completed the survey. About 33, 69, 33, and $49 \%$ of respondents recognized an intern, resident, fellow, and attending as a doctor, respectively. Three quarters (76.1\%) felt it was important to be asked permission in advance of a resident assisting or performing surgery, and $21 \%$ indicated they would go elsewhere if they found that a resident would assist in, or perform their surgery. About 21,21 , and $58 \%$ of respondents would be upset or very

\section{Keywords}

- informed consent

- resident surgery

- academic medicine

- medical trainee upset if a resident was in the operating room, assisted in, or performed surgery without their permission, respectively.

Conclusion This survey demonstrates an overall willingness of this specific, largely confined patient population to receive supervised care from training physicians provided they are fully informed and educated on the role of those involved in their care.
\end{abstract}

Medical education hinges on a delicate balance between appropriately training future practitioners with graduated levels of autonomy and the desire of individual patients to receive the most competent care. Foundational to Western medical education is a "hidden contract" in society whereby

received

May 31, 2019

accepted after revision

July 3, 2019
DOI https://doi.org/

$10.1055 / \mathrm{s}-0039-1694770$

ISSN $2475-4757$. the indigent traditionally receive free or subsidized care by allowing training physicians to function in part as the providers. ${ }^{1}$ Changes in the health care system over the past several decades, including more recently widespread access to medical insurance, has necessarily strained this
Copyright $\odot 2019$ by Thieme Medical Publishers, Inc., 333 Seventh Avenue, New York, NY 10001, USA. Tel: +1(212) 584-4662.
License terms

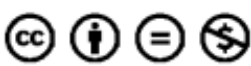


relationship. ${ }^{2}$ Thus one of the most fundamental questions surrounding medical education-"Who in society accepts the risk of trainee medical care?"-remains not only unanswered but largely unacknowledged.

There are no uniform protocols dictating how or even if patients are informed if a training physician is involved in their care and to what extent. A survey by ophthalmology residency program directors found that only $26 \%$ of programs had an established policy on disclosing resident involvement in surgery. ${ }^{3}$ We have no guidelines indicating what should be done if a patient requests trainees not be present. If we accept this request, then necessarily, the patients, who have the greatest understanding of the medical education system and are most vocal about it, will experience preferential treatment. Coupled with the historical tradition of utilizing our most vulnerable patients as the objects for clinical education, this is a matter that demands attention.

While there are many avenues in addressing this issue currently being explored and implemented including safety measures such as improving simulation exposure, trainee oversight, and a structured matriculation curriculum, an obvious-and largely disregarded-starting point is to determine the knowledge and preferences of our patients. With that in mind, we developed an internally validated survey for cataract surgery and consulted patients at the Veterans Affairs (VA) Hospital in Lexington, KY. These patients serve as the primary source of resident ophthalmologist surgery exposure at the University of Kentucky. The purpose of this survey was three-fold: to determine our patients' knowledge level about the medical education system, their preferences regarding who provides treatment, and how strongly they would react if they found certain members of the care team were involved without their consent.

\section{Materials and Methods}

This is a prospective, nonrandomized, observational trial of a convenience sample of patients referred to the VA Ophthalmology Clinic in Lexington, KY, between January 1, 2015 and June 1, 2017 for a cataract evaluation. The clinic is on the medical campus at the University of Kentucky and provides roughly 9,000 clinical encounters and 850 cataract surgeries per year. The clinic and operating rooms are staffed by resident and attending physicians at the University of Kentucky. Attending physicians provide direct supervision of all surgical procedures.

All patients were recruited to participate in a survey administered by one of the study personnel at the time of their initial evaluation. Patients were excluded if they had undergone any prior ophthalmic surgeries at a VA facility. The clinical chart of each patient was then reviewed and patients' age, gender, and number of prior visits in the ophthalmology clinic were recorded.

A pilot study was initially conducted of 10 eligible patients to internally evaluate the study and determine the questionnaire's feasibility and acceptability. A final 31-question survey was developed, based in part and modified from prior surveys. ${ }^{4,5}$ (- Supplementary Data)
This study was performed with approval from the Institutional Review Board at the VA Ophthalmology Clinic in Lexington, KY. This study was also approved by all residents and faculty at the University of Kentucky and VA Department of Ophthalmology. Given the concern that more informed patients may be less likely to allow trainee involvement in care and the priming nature of these questions, we greatly appreciate the willingness of the faculty and residents to risk the loss of cataract surgical experience to complete this study.

Responses to the survey questions were recorded as percent frequency. Correlations between two survey questions were based on a Chi-square test for contingency tables with statistical significance determined at the 0.05 level. The data were analyzed using PC-SAS version 9.4 (SAS Institute Inc., Cary, NC).

\section{Results}

A total of 123 patients were recruited, 10 of which participated in the pilot study and 17 of which were excluded because they were unable or unwilling to complete the entire questionnaire. Therefore, 96 patients' surveys were analyzed. The mean age was $69.8 \pm 8.1$ years, all but two patients were male, and the mean number of prior ophthalmology visits was $1.2 \pm 0.52$. Fifty-one and $41 \%$ of patients had previously received care or undergone surgery at a teaching hospital, respectively.

\section{Assessment of Knowledge of Medical Education System}

The first 19 questions queried patients on their knowledge of the medical education system. Three quarters $(74.8 \%)$ of those surveyed were very confident in their responses to these questions. Ninety percent of respondents recognized a medical student is not a doctor, while $33,69,33$, and $49 \%$ of respondents recognized an intern, resident, fellow, and attending as a doctor, respectively (-Fig. $\mathbf{1}$ ). Responses to the remaining questions are listed in -Table 1. Of note, $64 \%$ of respondents believed a resident had completed medical school, 51\% affirmed that they required supervision when caring for patients, and $41 \%$ indicated that residents are always supervised when caring for patients.

\section{Patient Preferences Regarding Providers of Medical Care}

Ninety-five percent of patients felt it was important to know the training of their doctor, while $61 \%$ claimed that they usually know if their caregiver is a student, resident, or attending.

\section{Comfort with Resident Involvement in Care}

The final questions assessed respondents comfort level with residents' involvement in care. Forty-nine percent agreed that being a patient at a teaching hospital means that residents will be involved in all aspects of care and 58\% felt it was important that residents have the opportunity to perform surgery during training. Twenty-one percent of those surveyed indicated they would seek treatment at a nonteaching hospital if they found out that a resident would assist in or perform their cataract surgery. Three quarters $(76.1 \%)$ felt it was important or extremely important to be asked permission in advance of a 


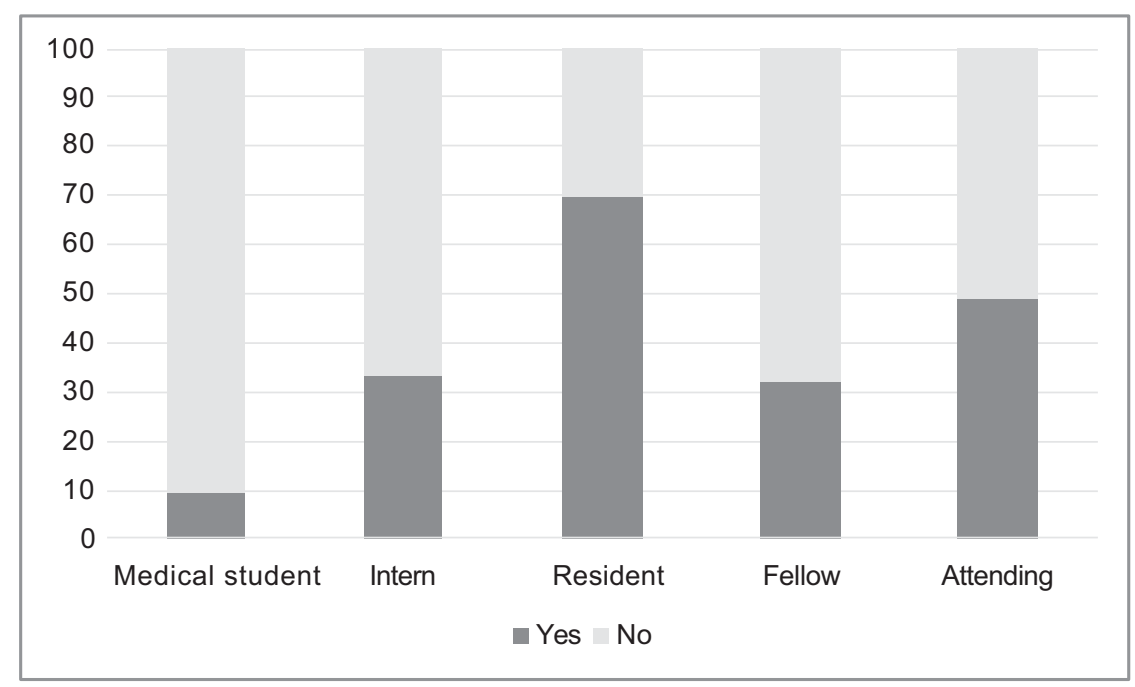

Fig. 1 Survey responses for the questions asking whether medical student, intern, resident, fellow, and attending are medical doctors. The vertical scale is percentage of respondents answering yes or no.

Table 1 Survey responses to questions assessing knowledge of medical education system

\begin{tabular}{|l|l|l|}
\hline & Yes (\%) & No (\%) \\
\hline $\begin{array}{l}\text { Does an attending require supervision } \\
\text { by a resident? }\end{array}$ & 51.1 & 48.9 \\
\hline Has a resident completed medical school? & 64.2 & 35.8 \\
\hline $\begin{array}{l}\text { Is a resident the most highly trained } \\
\text { doctor in the clinic? }\end{array}$ & 24.0 & 76.0 \\
\hline $\begin{array}{l}\text { Is an intern more highly trained than a } \\
\text { fellow? }\end{array}$ & 37.9 & 62.1 \\
\hline $\begin{array}{l}\text { Does a resident require supervision } \\
\text { when caring for patients? }\end{array}$ & 51.0 & 49.0 \\
\hline $\begin{array}{l}\text { Does an attending give orders to a } \\
\text { resident? }\end{array}$ & 37.6 & 62.4 \\
\hline Is the attending in charge of the clinic? & 28.0 & 72.0 \\
\hline $\begin{array}{l}\text { Are medical students, residents, and } \\
\text { interns at different levels of training? }\end{array}$ & 94.7 & 5.3 \\
\hline $\begin{array}{l}\text { Can a resident perform medical } \\
\text { procedures without supervision? }\end{array}$ & 46.8 & 53.2 \\
\hline $\begin{array}{l}\text { Is a resident always supervised when } \\
\text { caring for patients? }\end{array}$ & 41.5 & 58.5 \\
\hline Is the resident in charge of the clinic? & 28.0 & 72.0 \\
\hline $\begin{array}{l}\text { Has an attending completed all medical } \\
\text { training required for unsupervised } \\
\text { patient care? }\end{array}$ & 50.0 & 50.0 \\
\hline $\begin{array}{l}\text { Does a resident require years of training } \\
\text { to become an attending? }\end{array}$ & 65.2 & 34.8 \\
\hline $\begin{array}{l}\text { You feel very confident about your } \\
\text { responses to the previous section. }\end{array}$ & 74.8 & 25.2 \\
\hline
\end{tabular}

resident assisting or performing surgery, and $44 \%$ agreed they would allow a resident to perform their surgery if asked in advance. About 21, 21, and 58\% of respondents would be upset or very upset if a resident was in the operating room, assisted in, or performed surgery without their permission, respectively. Regarding who should seek permission for resident involvement in surgery, $80,25,22$, and $9 \%$ of respondents felt it should be the attending, resident, any licensed physician, and nurse, respectively (-Table $\mathbf{2}$ ).

\section{Associations between Responses}

Respondents who felt it was important to know the training level of their physician also felt strongly that it was important to be asked permission in advance for a resident to be involved in surgery $(p<0.001)$ and would be upset if a resident performed their surgery without permission $(p=0.037)$. Those respondents, who had previously received care at a teaching hospital, felt it was more important that residents should be able to perform surgery during their training $(p=0.028)$. Participants who disagreed that a standard consent form provides sufficient information to understand if a resident participates in surgery were also less likely to allow a resident participate in the surgery if asked in advance $(p=0.005)$. Respondents who indicated that residents do not require supervision when providing care were also more likely to be upset if a resident performed their surgery without permission $(p=0.0256)$ and were more likely to disagree to have a resident participate in surgery if asked in advance $(p=0.028)$.

\section{Discussion}

The traditional and covert ways we involved in training physicians in medical care has the potential to erode the fabric of public trust in academic medicine. This is an ignored conversation that needs to be brought to light to allow our institutions and society itself to decide the best way to train future physicians in an era of widespread and increasingly equitable access to health care. To provide a small measure of context, the current study was conducted in a largely confined population of veterans to determine their preferences regarding trainee 
Table 2 Survey responses to questions assessing comfort level with resident involvement in care

\begin{tabular}{|l|l|l|l|l|l|}
\hline & $\mathbf{1}$ & $\mathbf{2}$ & $\mathbf{3}$ & $\mathbf{4}$ & $\mathbf{5}$ \\
\hline $\begin{array}{l}\text { How important do you feel that resident doctors have the opportunity to perform } \\
\text { surgery during their training? }\end{array}$ & 1.2 & 25.6 & 15.6 & 30.0 & 27.8 \\
\hline $\begin{array}{l}\text { How likely would you be to seek treatment elsewhere, at a place where residents were not } \\
\text { involved, if you found out that a resident would assist in or perform your surgery? }\end{array}$ & 18.9 & 16.7 & 43.3 & 12.2 & 8.9 \\
\hline $\begin{array}{l}\text { How much do you agree or disagree that being a patient at a teaching hospital means } \\
\text { that resident physicians will be involved in all aspects of medical care? }\end{array}$ & 6.5 & 15.2 & 29.3 & 31.5 & 17.4 \\
\hline $\begin{array}{l}\text { If asked in advance, how likely would you be to let a resident assist in or perform your } \\
\text { surgery? }\end{array}$ & 9.8 & 18.5 & 28.3 & 32.6 & 10.9 \\
\hline How important is it to be asked in advanced for a resident to assist in or perform your surgery? & 4.3 & 9.8 & 9.8 & 34.8 & 41.3 \\
\hline Ifyour permission were not requested, how upset would you be if you found the resident was: & & & & & \\
\hline In the operating room during surgery? & 52.7 & 8.6 & 18.3 & 14.0 & 6.5 \\
\hline Assisted in your surgery? & 51.6 & 8.8 & 30.8 & 9.9 & 9.9 \\
\hline Performed your surgery? & 17.6 & 11.0 & 13.2 & 25.3 & 33.0 \\
\hline $\begin{array}{l}\text { How much do you agree or disagree that a standard consent form provides all the } \\
\text { information needed for you to understand a resident may assist or perform your surgery? }\end{array}$ & 7.6 & 18.5 & 32.6 & 32.6 & 8.7 \\
\hline
\end{tabular}

Note: responses are presented as percentages on a Likert's-type scale, with $1=$ strongly negative, $3=$ neutral, and $5=$ strongly positive.

involvement in surgical care. We found these patients are mostly willing to accept some of the societal risk in training physicians, $79 \%$ would not seek care elsewhere if a resident participated in their surgery, but they also want to be informed and need better education on the role of each individual on the medical team. While less than half $(44 \%)$ of respondents would allow a resident to perform their procedure if asked in advance, many of the following individuals had limited insight into the exact role and training of resident physicians: $36 \%$ did not believe residents have completed medical school and 49\% thought residents did not require supervision when providing care. Unsurprisingly, these responses were correlated $(p<$ 0.001 ), underscoring the importance of educating our patients of the medical training environment when residents are involved in care. Patients uniformly stated a desire to know the training of their provider, yet only $61 \%$ claimed to be regularly informed of this information.

These results are quite similar to prior studies. A 2008 survey of patients presenting to a faculty clinic at an academic ophthalmology department found that $76 \%$ would not seek treatment elsewhere if a resident performed their cataract surgery and $49 \%$ would permit a resident to perform their surgery if asked in advance. ${ }^{4}$ A survey of parents presenting to an academic pediatric ophthalmology practice found that $77 \%$ would agree to residents assisting and $36 \%$ to residents performing their child's strabismus surgery. ${ }^{6}$ A 2006 survey of a combination of resident, private practice and pediatric ophthalmology clinics found that 85,58 , and $56 \%$ of respondents correctly knew whether a medical student, resident, and attending were medical doctors, respectively. Twenty-nine percent agreed that the attending was in charge of the clinic and $32 \%$ knew that a resident is always supervised when providing care. Nearly three-fourths of patients (72\%) felt comfortable being treated by a supervised physician in training, although pediatric clinic respondents were significantly more likely to agree with this statement than those in the resident clinic. ${ }^{5}$ Another survey of patients in an academic orthopaedic outpatient clinic found that one-fourth of patients (26\%) did not believe a resident has completed medical school, $57 \%$ agreed that residents require no supervision when caring for patients, and $76 \%$ stated comfort with allowing training doctors to learn on them as long as they are supervised. ${ }^{7}$

It has been previously reported that patients are decreasingly willing to allow trainee involvement in surgical care, as much they are educated on the role of the resident. ${ }^{8}$ This in part may explain the reticence of programs, institutions, and our academic societies to formulate guidelines or policies on disclosing trainee involvement in care. Indeed, our study and others, while overall encouraging regarding patient willingness to share the risk of trainee education, still suggest that 20 to $30 \%$ of patients would attempt to seek care elsewhere if informed that a resident would perform their procedure. In an era of increasing transparency and a patient-centered approach to informed decision-making, ${ }^{9}$ these concerns are clearly insufficient reasons to avoid full disclosure of the role of respective members of the care team. ${ }^{10}$ However, any strategy addressing trainee disclosure should also provide guidance on how to proceed when a patient refuses to allow a trainee participate in their care. Since the majority of resident surgical training occurs at teaching hospitals, the patients preferentially affected by any standards are more likely in a captive or historically vulnerable population. ${ }^{11}$ And as this study demonstrates in one such group, there exists limited appreciation of the academic health care training hierarchy, raising the possibility that many of these patients have both limited prior knowledge and limited disclosure of the role of their providers. To mitigate this risk, it is important that patients at all institutional educational sites be offered similar education and opportunities to determine their willingness to participate in trainee-involved care. 
e34 Patient Preferences to Involve Trainees in Surgical Care Moore et al.

\section{Limitations}

There are several important limitations to these findings. This study is from a single-center and single-surgical subspecialty, and the sample size was modest. The survey was novel, although based in part on prior surveys and internally validated. It was administered just prior to a clinical cataract evaluation, leading to potential response bias and did not evaluate responses following any surgical procedures. Because patients were asked first about their medical knowledge prior to preferences on surgical care, there could have been an order effect bias in the latter responses. They all point to the need for further study locally and nationally. Going forward, we plan to expand this survey to a broader group of patients and determine the effect of several educational interventions in improving communication and perception of care provided.

\section{Conclusion}

In conclusion, our survey demonstrates an overall willingness of this specific population to receive supervised surgical care from training physicians. However, these patients want to be fully informed and educated on the role and responsibilities of those involved in their care. Hopefully our community will soon take up the task of systemically addressing how we ensure equitable access to care and risk in academic medicine. During this process, it is imperative that we consider the preferences and perspective of our patients.

Conflict of Interest

None declared.

\section{References}

1 Foucault M. The Birth of the Clinic: An Archaeology of Medical Perception. Sheridan AM, translator. New York, NY: Tavistock Publications Limited; 1973

2 O'Shea JS. Individual and social concerns in American surgical education: paying patients, prepaid health insurance, Medicare and Medicaid. Acad Med 2010;85(05):854-862

3 Chen AJ, Scott IU, Greenberg PB. Disclosure of resident involvement in ophthalmic surgery. Arch Ophthalmol 2012;130(07): 932-934

4 Wisner DM, Quillen DA, Benderson DM, Green MJ. Patient attitudes toward resident involvement in cataract surgery. Arch Ophthalmol 2008;126(09):1235-1239

5 Guffey R, Juzych N, Juzych M. Patient knowledge of physician responsibilities and their preferences for care in ophthalmology teaching clinics. Ophthalmology 2009;116(09): 1610-1614

6 Andrews H, Soni A, Green M, Ely A, Quillen D. Parent attitudes toward resident involvement in their child's strabismus surgery. J AAPOS 2018;22(04):262-265.e3

7 Unruh KP, Dhulipala SC, Holt GE. Patient understanding of the role of the orthopedic resident. J Surg Educ 2013;70(03): 345-349

8 Porta CR, Sebesta JA, Brown TA, Steele SR, Martin MJ. Training surgeons and the informed consent process: routine disclosure of trainee participation and its effect on patient willingness and consent rates. Arch Surg 2012;147(01):57-62

9 Spatz ES, Krumholz HM, Moulton BW. The new era of informed consent: getting to a reasonable standard through shared decision making. JAMA 2016;315(19):2063-2064

10 Drolet BC, Brower JP, Miller BM. Trainee involvement in patient care: a necessity and reality in teaching hospitals. J Grad Med Educ 2017;9(02):159-161

11 Naseri A. Patient consent for resident involvement in surgical care. Arch Ophthalmol 2012;130(07):917-918 